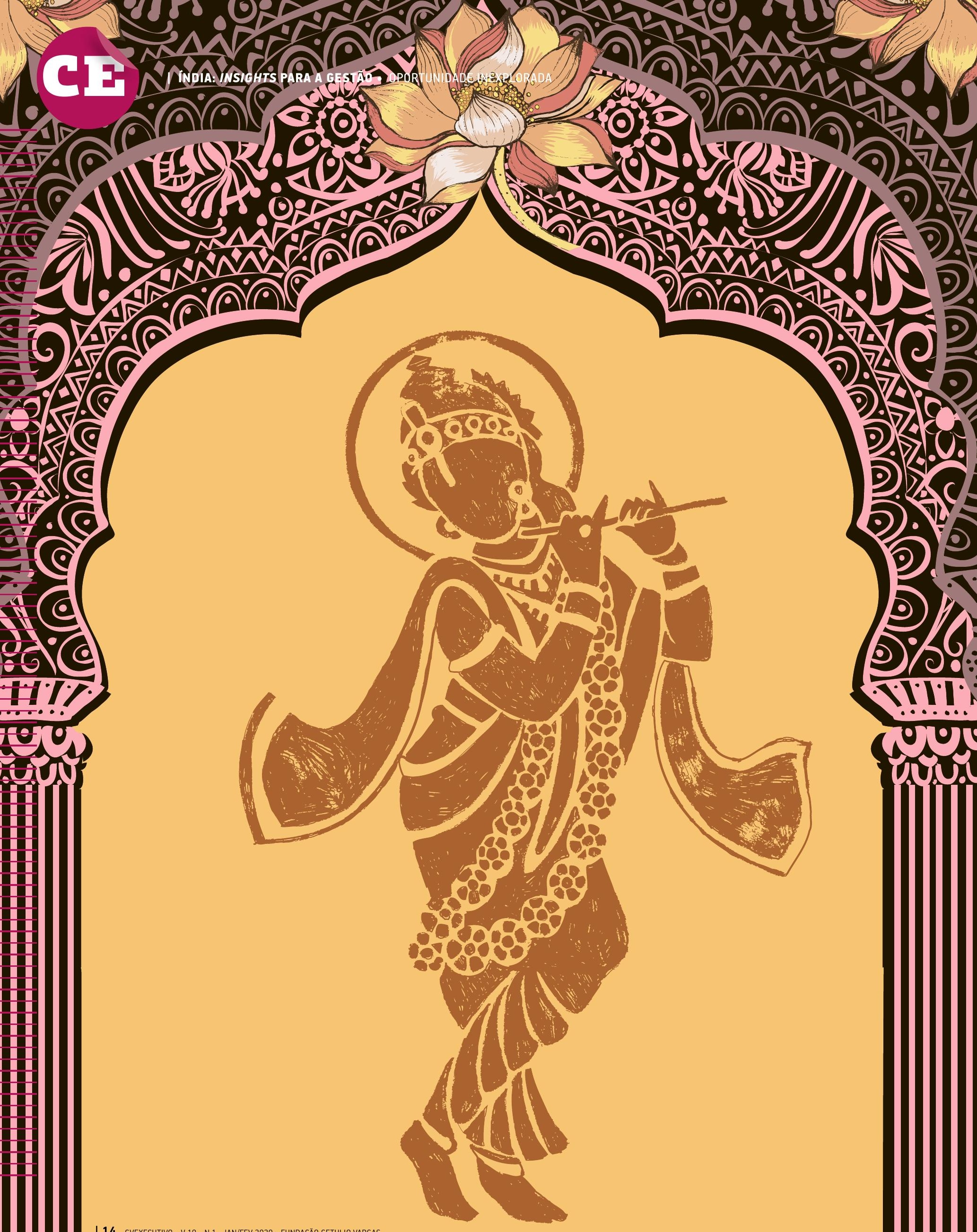




\section{OPORTUNIDADE INEXPLORADA}

| POR UMESH MUKHI

\section{As relações entre Brasil e Índia podem se fortalecer com cooperação governamental para temáticas específicas, iniciativas educacionais conjuntas, inserção de suas marcas nos dois mercados emergentes e maior intercâmbio cultural.}

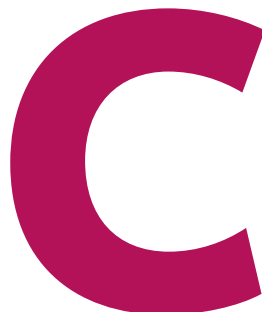

omo professor indiano da Escola de Administração de Empresas de São Paulo da Fundação Getulio Vargas (FGV EAESP), muitas vezes sou questionado sobre como vejo o desenvolvimento da relação entre Índia e Brasil no contexto de duas economias emergentes. Ambos os países são como gigantes em lados opostos do Atlântico, que, ao olhar um para o outro, reconhecem suas proezas, admiram suas transições democráticas, mas ainda estão longe de catalisar sua parceria.

Para a Índia, os Estados Unidos são o parceiro comercial dominante na América do Norte, e o Brasil tem se tornado seu aliado econômico mais importante em toda a região da América Latina e do Caribe (ALC). No entanto, a situação pode ser diferente para o Brasil, que, por causa das suas exportações ancoradas em produtos de base, volta-se principalmente à China.

Não obstante, assistimos ao interesse crescente do Brasil em cooperar com a Índia nas áreas de ciência e tecnologia. Também houve aumento de visitas oficiais e de acordos governamentais para a maior colaboração na agricultura, na tecnologia espacial e no setor farmacêutico. Podem-se citar a recente reunião dos chefes de Estado indiano e brasileiro durante a Cúpula dos BRICS em Brasília e o convite ao presidente brasileiro para visitar a Índia com o objetivo de participar do Dia da República. Empresas indianas vêm investindo no Brasil em setores como os de tecnologia da informação, farmacêutico, de energia, do agronegócio, da mineração e de engenharia/automobilístico. No setor de tecnologia da informação (TI), por exemplo, empresas como a Tata Consultancy Services e a Wipro Technologies vêm atuando com diversos parceiros educacionais, em diferentes partes do Brasil, para melhorar a qualificação da mão de obra e desenvolver o ecossistema de TI no país.

\section{PRINCIPAIS DESAFIOS}

Até a última década, tanto Brasil quanto Índia conseguiram acelerar seu crescimento por meio de investimentos em setores estratégicos, ou seja, agronegócios e serviços. De acordo com o Atlas de Complexidade Econômica, de Harvard, ambos os países estão próximos em termos de complexidade de suas exportações: entre 133 países, o Brasil encontra-se no $48^{\circ}$ lugar, enquanto a Índia está na $45^{\mathrm{a}}$ posição. De acordo com o indicador, as duas nações ainda precisam mover suas atividades econômicas de setores de baixa para alta produtividade, como o têxtil, o eletrônico e o de produção de máquinas. Apesar da semelhança, as perspectivas são distintas para os dois países. Entre as 133 nações analisadas, o Brasil caiu 22 posições no ranking da 
Harvard entre 1995 e 2017 e está em $42^{\circ}$ lugar em termos de potencial de utilização das capacidades desenvolvidas para aumentar a complexidade de suas exportações. A Índia, ao contrário, ganhou 18 posições no mesmo período e ocupa a primeira colocação em temos de perspectivas de inserção de produtos mais complexos em sua pauta de exportações.

$O$ índice Ease of doing business (Facilidade de fazer negócios), do Banco Mundial, também mostra as diferenças entre Brasil e Índia. Trata-se de um indicador que reflete o estado das economias versus as mudanças estruturais que cada uma tem feito para melhorar suas condições regulatórias para os investidores. No ranking de 2019, a Índia ficou em $63^{\circ}$ lugar, enquanto o Brasil ocupou a $124^{\mathrm{a}}$ posição (veja no quadro da página seguinte).

Especialmente na última década, a economia brasileira pagou um preço alto por suas turbulências políticas. Além disso, a incapacidade do Estado de fazer reformas sistêmicas para incentivar o crescimento e o investimento impacta o país, que está perdendo competitividade. O crescimento projetado pelo Atlas de Complexidade Econômica para a economia brasileira é de apenas 3,4\% ao ano na próxima década. Apesar de estar em melhor posição e ter crescido de forma sustentável nos últimos anos, a Índia está vivenciando uma desaceleração e estima-se que cresça $5,5 \%$ nos próximos 10 anos. Após uma série de experiências macroeconômicas, como a desmonetização (em 2016, as cédulas de 500 e 1.000 rúpias, que representavam perto de $90 \%$ do dinheiro em circulação, passaram a ser consideradas inválidas) e a reforma fiscal, a economia indiana ainda não sentiu todos os efeitos de tais medidas.

Além disso, pode-se também especular que ambos os países permaneceram na zona segura de crescimento de uma economia baseada em commodities ou serviços que dependem da demanda externa, o que pode ser perigoso e inibir o crescimento. Por exemplo, um abalo na economia da China afetaria severamente as exportações brasileiras, enquanto mudanças na política americana para vistos teriam o potencial de causar sérios estragos no setor de TI da Índia.

\section{IDEIAS PARA MAIOR COOPERAÇÃO}

Se o Brasil conseguir entender a Índia e vice-versa, ambos podem aprender com as melhores práticas de setores que vêm crescendo nesses países, fortalecer suas economias e diminuir suas dependências no cenário internacional. Destaco a seguir algumas ideias que poderiam ser cogitadas para estimular o intercâmbio:

\section{Promover a diplomacia e a cooperação governamental}

Brasil e Índia precisam envolver seus Estados no esforço de cooperação econômica. A Índia tem muito a aprender sobre agricultura com estados como Mato Grosso, enquanto o Brasil pode tirar lições da experiência do estado de Querala sobre como atingir uma taxa de alfabetização mais alta, ali conquistada com o método construtivista, um sistema de avaliação abrangente e contínuo e a inserção de TI na sala de aula. A Índia ainda poderia ser exemplo para o Brasil sobre a modalidade ferroviária como uma infraestrutura eficaz e oportunidade de empregabilidade para promover o crescimento interno.

A diplomacia no nível municipal poderia também ser estimulada, com a visita de prefeitos de cidades brasileiras a cidades indianas para a aprendizagem e troca de melhores políticas de administração pública e urbana. Por exemplo, capitais brasileiras como São Paulo, Belo Horizonte, Cuiabá, Curitiba, Brasília e Porto Alegre têm potencial para fazer intercâmbio com cidades de perfil semelhante na Índia, como Bangalore, Mumbai, Nova Déli, Indore, Ahmedabad e Hyderabad.

\section{Incentivar a cooperação educacional e o intercâmbio de talentos}

Língua e distância ainda são barreiras dominantes para os indianos e brasileiros enxergarem a cooperação educacional como uma possibilidade, que está limitada aos níveis de mestrado e doutorado. Ambos têm procurado os Estados Unidos e a Europa para intercâmbios educacionais, no entanto nenhum deles tem desenvolvido seus centros educacionais como destino.

Se o futuro do crescimento está na Ásia, na África e na América do Sul, então a educação deve ser o centro para que isso aconteça. Os alunos que se formam são decisivos no desenvolvimento de novas conexões entre os países. No caso da Índia, a diáspora de profissionais em direção aos Estados Unidos tem tido enorme papel na contribuição das relações entre as duas nações. Como exemplo, tanto o chief executive officer (CEO) do Google, Sundar Pichai, como o da Microsoft, Satya Nadella, são indianos. Poderíamos imaginar o desenvolvimento de programas conjuntos entre Brasil e Índia para desenvolver talentos para as empresas dos dois países?

\section{Investir em produtos de consumo de massa}

A maioria do comércio entre Índia e Brasil é do tipo business to business (B2B). Para romper com a estagnação econômica, é necessário que os dois países comecem a explorar seus horizontes além dos mercados tradicionais, ampliando suas marcas 


\section{POSIÇÃO DA ÍNDIA E DO BRASIL NO RANKING GERAL DO EASE OF DOING BUSINESS E POR ITENS AVALIADOS}

\section{Indicador}

Facilidade de fazer negócios (Ease of doing business)

\begin{tabular}{|c|c|c|}
\hline $\begin{array}{l}\text { POSIÇÃO DA ÍNDIA E DO BRASIL I } \\
\text { RANKING GERAL DO EASE OF DO } \\
\text { BUSINESS E POR ITENS AVALIAD }\end{array}$ & गाтाтाтाтाтा & \\
\hline Indicador & Posição da Índia & Posição do Brasil \\
\hline Facilidade de fazer negócios (Ease of doing business) & 63 & 124 \\
\hline Abertura de empresas & 136 & 138 \\
\hline Obtenção de alvarás de construção & 27 & 170 \\
\hline Obtenção de eletricidade & 22 & 98 \\
\hline Registro de propriedade & 154 & 133 \\
\hline Obtenção de crédito & 25 & 104 \\
\hline Proteção de investidores minoritários & 13 & 61 \\
\hline Pagamento de impostos & 115 & 184 \\
\hline Comércio internacional & 68 & 108 \\
\hline Execução de contratos & 163 & 58 \\
\hline Resolução de insolvência & 52 & 77 \\
\hline
\end{tabular}

FONTE: BANCO MUNDIAL

e seus produtos para os consumidores finais. A crescente classe média indiana interessa-se cada vez mais por marcas internacionais e, embora seja um mercado competitivo, as marcas brasileiras podem se diferenciar e adentrar nesse segmento de massa. Da mesma forma, as marcas indianas podem alavancar sua expertise especialmente em produtos de beleza e bem-estar, que estão em demanda no Brasil.

\section{Apoiar o intercâmbio cultural}

Os brasileiros também têm expressado curiosidade pela cultura, pela religião, pelas artes cênicas e pela filosofia da Índia. Lembro-me do meu encontro com o embaixador brasileiro na Índia em 2017. Ele rememorou sua vivência quando visitou a cidade de Varanasi para acompanhar as eleições e a chamou de "inesquecível" e "uma experiência completamente diferente".

O reflexo do interesse do Brasil pela cultura indiana pode ser visto em vários níveis. A presença do Centro Cultural Swami Vivekananda, do governo indiano, em São Paulo, estimulou a difusão de música, ioga, cinema, literatura, ciência da saúde ayurveda e filosofia gandhiana. A novela brasileira Caminho das Índias e o mais recente documentário da TV Globo sobre o Rio Ganges também refletem e estimulam a curiosidade dos brasileiros em conhecer a cultura.

Prefeitos de cidades brasileiras poderiam explorar os benefícios da cultura indiana de bem-estar e harmonia, oferecendo espaço em parques e centros culturais, promovendo lugares para ioga, dança e outras formas de arte do país.
A cultura é uma ótima maneira de promover viagens e turismo para ambas as nações. É lamentável que não haja voos diretos de nenhuma das companhias nacionais. Esse pode ser outro movimento para facilitar a confluência de culturas entre a Ásia e a América do Sul.

\section{CONCLUSÃO}

Segundo o economista Ricardo Amorim, a Índia deve ser a próxima China para o Brasil. A urbanização e o crescimento da classe média indiana terão efeito semelhante, ou até maior, nos negócios brasileiros comparativamente ao movimento que aconteceu no território chinês de 1980 para cá. Índia e Brasil têm a oportunidade de aprender e crescer mutuamente. Para isso, precisam se envolver não só na cooperação em nível governamental, mas também explorar meios pouco ortodoxos de cooperação para desenvolver sua economia e sociedade.

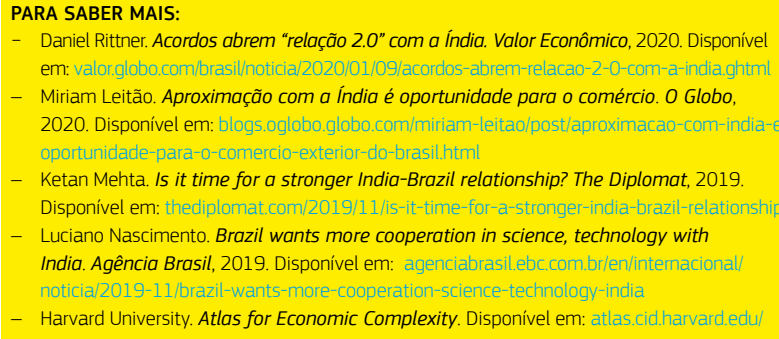

UMESH MUKHI > Professor da FGV EAESP > umesh.mukhi@fgv.br 